\title{
“O TRABALHO DE CAMPO EM HISTÓRIA DAS RELAÇÕES INTERNACIONAIS ACONTECE EM GRANDE MEDIDA NOS ARQUIVOS, OU DEVERIA PASSAR PELOS ARQUIVOS".
}

\author{
Entrevista com Norma Breda dos Santos ${ }^{1}$
}

\section{Revista Malala (RM)}

Professora Norma, toda pesquisa acadêmica possui suas dificuldades e peculiaridades. Em se tratando de Oriente Médio e Mundo Muçulmano - em linhas gerais - o que se destaca?

\section{Norma Breda dos Santos (NBS)}

Provavelmente, o que se destaca, de maneira geral, é a falta de um conhecimento aprofundado sobre o Oriente Médio e o Mundo Muçulmano. Esse traço agudizou-se e se manifestou mais claramente nas últimas duas décadas, com a alta volatilidade e a densidade política que os dois temas ganharam. Arrisco-me a afirmar que, na pesquisa acadêmica, essas características são menos marcantes no campo da História e da Antropologia, e mais visíveis no campo das Relações Internacionais, que tende a enfatizar mais a preocupação com a estabilidade e a segurança internacional e, portanto, rapidamente enxerga o Oriente Médio e o Mundo Muçulmano como ameaças. Não que isso tenha a ver com características intrínsecas da área de Relações Internacionais e sim com a maneira apressada com que se tem feito análises e diagnósticos sobre esses temas. Há cem anos, era celebrado o Acordo Sykes-Picot (1916), entre Grã-Bretanha e França. Para além do mundo acadêmico, é interessante observar como no Ocidente, a população em geral, ainda que se sinta muito atingida pela presença de refugiados e pela ameaça de ataques terroristas, não parece relacionar essas questões com Sykes-Picot, com a história colonial nem com a política neocolonialista e os frequentes desacertos das lideranças políticas da Grã-Bretanha e da França. Ademais, o que tem sido muito apontado pelos especialistas que têm uma formação mais humanista e crítica, é o olhar orientalista, na academia e fora dela, sobre o Oriente Médio e o Mundo Muçulmano, carregado de estereótipos, generalizações e estigmas.

\section{RM}

Geralmente a grande expectativa é que o pesquisador faça "trabalho de campo", ou seja, ele deveria ir, conhecer e ver de perto seu objeto de pesquisa. Em se tratando de Oriente Médio e Mundo Muçulmano (OMMM), muitas vezes isso não é possível. Isso compromete o resultado? Como solucionar essa dificuldade da demanda empírica?

\footnotetext{
${ }^{1}$ Professora associada e membro do corpo docente do Programa de Pós-Graduação em Relações Internacionais do Instituto de Relações Internacionais da Universidade de Brasília (UnB). Entrevista realizada por e-mail no dia 10/07/2017 com Natalia Nahas Calfat, membro do Conselho Editorial da Revista Malala e Ariel Finguerut, membro do Conselho Científico da revista. A entrevista foi revisada por Cila Lima, membro do Conselho Editorial da Revista Malala, em 23/08/2017.
} 


\section{NBS}

O trabalho de campo em História das Relações Internacionais acontece em grande medida nos arquivos, ou deveria passar pelos arquivos. Em minha tese de doutorado, sobre a participação brasileira na Liga das Nações, consultei os arquivos da Liga e os arquivos diplomáticos do Brasil, da Inglaterra e da França. Principalmente sobre a saída do Brasil da Liga, em 1926, cheguei a conclusões sensivelmente diferentes das que prevalecem na historiografia brasileira e que continuam a informar os manuais sobre política externa brasileira. Mesmo no Itamaraty, acredito que a percepção sobre a passagem do Brasil na Liga das Nações é ainda, na minha modesta opinião, equivocada, dando muita ênfase às decisões do então presidente da República, Artur Bernardes, que deveriam ser colocadas em perspectiva. Penso que esse aspecto merece atenção porque acaba-se por essa via assumindo uma postura de certa forma "colonizada", com perdão pela utilização de um termo forte, sobre a diplomacia brasileira, "incompetente" vis-à-vis os homens de Estado europeus "experientes" e "sábios". Enfim, como mencionado na pergunta, há realmente uma questão relacionada à demanda empírica, que entendo, sim, como uma questão relacionada à necessidade de ir a campo, para fazer trabalho em arquivos notadamente. Outro aspecto que eu gostaria de mencionar, que se relaciona à pergunta mais amplamente, diz respeito aos âmbitos da pesquisa em Relações Internacionais e de História das Relações Internacionais, que teriam uma orientação predominantemente e demasiadamente centrada no Estado, na diplomacia, na perspectiva top-down. Entretanto, há nessas áreas teoria e metodologia que dão suporte a pesquisas com ênfase nos processos sociais, nas relações entre os indivíduos, entre grupos sociais, entre populações. Nesse sentido, apenas um exemplo que me ocorre, é a tese de doutorado de Monique Sochaczewski, Do Rio de Janeiro a Istambul, que acaba de ser publicada como livro pela Funag. É um trabalho de fôlego, que vai da metade do século XIX até nos anos 1920. Monique utilizou fontes diplomáticas e não diplomáticas do Brasil e da Turquia, então Império Otomano, cujas complexidades históricas, políticas e culturais demandam do pesquisador um trabalho muito cuidadoso. A tese trata do relacionamento entre o Brasil e o Império Otomano, marcado pelas levas de imigrantes chegados ao Brasil do Império Otomano. Voltando ao que eu dizia sobre o universo que abarca a História das Relações Internacionais: existe uma rica bibliografia brasileira sobre a imigração vinda de vários continentes para o Brasil nos séculos XIX e XX. O trabalho de Monique integra esse componente sociocultural, o conteúdo dessa abundante bibliografia e de novas fontes documentais ao universo das relações diplomáticas entre Brasil e Império Otomano, muito mais amplo e complexo do que uma visão superficial faria supor. Essa imigração representava um problema para o governo brasileiro, já não correspondia ao projeto de europeizar e embranquecer a população do Brasil. Mas era também um problema para o Império Otomano, que perdia mão de obra e era chamado a agir diplomaticamente face às sérias dificuldades enfrentadas por seus súditos no Brasil.

Por fim, é preciso ter em mente que a pesquisa envolvendo o relacionamento entre o Brasil e os países do Oriente Médio é ainda tremendamente incipiente, e essa observação 
é válida para muitas regiões e temas. Não é difícil apontar estudos históricos que se tornaram referência por terem tratado de aspectos desconhecidos ou pouco conhecidos até então. A historiografia brasileira é sabidamente vastíssima sobre o período Vargas (1930-1945), mas se pensamos na política externa e nas relações internacionais do Brasil com o Oriente Médio a coisa muda de figura. 0 Anti-semitismo na era Vargas, da professora Maria Luiza Tucci Carneiro, publicado no final dos anos 1980, documenta a existência de circulares secretas no âmbito do Itamaraty que impediram a entrada no Brasil de judeus europeus perseguidos pelo nazismo. É um estudo importante, que teve o mérito de provocar um debate sobre o antissemitismo no Brasil dos anos 1930. Sobre o tema, e com interpretações diferentes, creio ser indispensável mencionar pelo menos os trabalhos posteriores de Jeffrey Lesser e Marcos Chor Maio. O livro de Seme Taleb Fares, de 2007, O Pragmatismo do Petróleo, publicado em 2009, trata das relações perigosamente intensas ao longo das décadas de 1970 entre o Brasil e o Iraque. Mostra que mesmo no governo Sarney, governo civil, as relações entre os dois países ainda eram muito próximas, envolvendo a cooperação nuclear, para não falar da venda de armas do Brasil ao Iraque. Documentos do Arquivo Histórico do Itamaraty e documentos publicados pelo ministério são fontes importantes desse trabalho.

\section{RM}

Sabemos que o acesso a fontes diplomáticas pode ser muito difícil em vários países do OM. E no Brasil?

\section{NBS}

Minha percepção é que o acesso tem melhorado. 0 Arquivo Histórico do Itamaraty no Rio de Janeiro guarda documentos de 1808 a 1960; o de Brasília a partir de 1960. Pode acontecer de um documento não estar no lugar adequado; aí é bem difícil encontrá-lo. Mas isso não é tão comum. 0 que acontece com frequência é encontrar-se uma referência a um documento, apenas a folha de rosto do documento. Sabe-se, então, que existe um documento que pode ser muito importante, mas o documento não está onde deveria. Não sei por que isso acontece. Não estou pensando em documentos classificados. Hoje com a Lei de Acesso à Informação é possível, embora não possa dizer que seja provável, que se consiga resolver esse problema. Não utilizei a LAI ainda. Há poucos meses foi publicado um bom artigo na Revista Brasileira de Política Internacional sobre a implementação da LAI pelo Itamaraty. Segundo esse trabalho, o Itamaraty precisaria atuar com maior transparência. Há vários artifícios que podem ser utilizados para não fornecer informações, desde a classificação da documentação até a interpretação da LAI de maneira restritiva, o que no médio e longo prazo não é bom para o próprio Itamaraty. Em fundos privados que foram depositados por vários diplomatas no CPDOC, no Rio de Janeiro, é possível ampliar a base documental, a depender naturalmente do tema da pesquisa. 


\title{
RM
}

Outra barreira é a língua. É preciso dominar o árabe - ou no limite a língua nativa - para de fato conseguir avançar com uma pesquisa sobre OMMM?

\begin{abstract}
NBS
É interessante conhecer o idioma local a fim de aprofundar a pesquisa. Da mesma forma, conhecer a região, os países médio-orientais. 0 diálogo com pesquisadores que vêm desses países ou que têm grande familiaridade com a vida nesses países é uma forma muito usual de avançar na pesquisa; não é só enriquecedor; é indispensável. 0 contato com a literatura produzida nesses países, mesmo de ficção, permite igualmente o encontro com a alteridade, a desnaturalização de nossas percepções sobre o outro e da nossa relação com o outro, e, na medida do possível, nos darmos conta do nosso anacronismo. É um esforço que não pode ser contornado; é o que nos permite problematizar certos temas, fazer perguntas profícuas.
\end{abstract}

\section{RM}

Há uma tradição na política externa brasileira específica para a região?

\section{NBS}

Não há uma tradição propriamente dita na política externa brasileira com relação ao Oriente Médio, mas a continuidade da diplomacia brasileira na defesa de certos princípios - como a solução pacífica de controvérsias, a autonomia e o direito dos povos e das nações à soberania, a valorização do direito internacional, o direito ao desenvolvimento - permitiu ao Brasil acertar mais do que errar em sua política externa para o Oriente Médio. Foi o que orientou as posições brasileiras no sentido de defender ao mesmo tempo a solução da questão palestina e o direito de existência de Israel, por exemplo.

Pode-se falar de uma diplomacia sobretudo reativa e, portanto, não parece haver um planejamento estratégico de médio e longo prazo para a região. Até algumas décadas atrás, não considerar o Oriente Médio como um tema relevante talvez fosse viável; hoje isso não é mais possível. Na diplomacia multilateral, provavelmente, há eixos mais claros e contínuos. Ainda que de forma praticamente simbólica, o Brasil participou da UNTSO (Organização das Nações Unidas para a Supervisão da Trégua), missão de observação criada em 1948 para atuar na Palestina; esteve ao longo de dez anos no Sinai participando da UNEF I (Força de Emergência das Nações Unidas), criada em consequência da Crise do Suez (1956); desde 2011, participa da UNIFIL (Força Interina das Nações Unidas no Líbano) comandando uma força-tarefa marítima com o objetivo principal de impedir a entrada de armas ilegais e contrabandos no Líbano. São cerca de 300 militares brasileiros estacionados em uma fragata ao longo da costa do Líbano.

Ainda no âmbito multilateral, vimos na década de 1970 um certo ativismo brasileiro na defesa dos direitos palestinos. É preciso ter em mente que após a Guerra dos Seis Dias (1967) e a ocupação de Israel de territórios palestinos, diminuiu muitíssimo o apoio 
internacional a Israel. Além disso, a partir da metade dos anos 1950, o movimento terceiro-mundista ganhou muito espaço na ONU. O governo Geisel ganhou visibilidade na ONU ao apoiar mais firmemente os direitos palestinos, processo que começou no governo anterior. Há uma bibliografia muito rica sobre o período, que insiste, porém, sobre algumas teses provavelmente equivocadas. Uma delas, a partir dos estudos de Moniz Bandeira, parte do pressuposto de que as relações do Brasil com os Estados Unidos explicavam-se por uma rivalidade histórica entre os dois países. Se lermos atentamente o trabalho de Moniz Bandeira sobre esse período, veremos que o historiador, especificamente sobre a presidência de Ernesto Geisel, não faz, na realidade, essa leitura e menciona um movimento de aproximação entre o Brasil e os Estados Unidos. Portanto, a busca da autonomia e da diversificação de parcerias do governo Geisel, de um lado, e relações de entendimento com os Estados Unidos não foram objetivos excludentes. Azeredo da Silveira sempre atribuiu muita importância ao relacionamento do Brasil com os Estados Unidos, mas relações respeitosas e não de subserviência por parte do governo brasileiro.

O livro de Matias Spektor, Kissinger e o Brasil, é fundamental para compreender-se o período. E volto ao meu mantra: é fundamental ir aos arquivos. Matias trabalhou com uma base documental muito ampla, acessível no Brasil e nos Estados Unidos, principalmente. Na tese de doutorado que deu origem ao livro, há esclarecimentos sobre o acesso à documentação de várias proveniências. Por exemplo, nos Estados Unidos Matias menciona uma extensa documentação da CIA relativa ao período 1945-1981, acessível desde 2003. Pouco depois, novos documentos do Departamento de Estado são liberados à consulta. No Brasil, o que não foi possível ter acesso nos Arquivos do Itamaraty - Matias conta da tese que sua solicitação de consulta a documentos secretos e ultrassecretos não foi deferida -, foi consultado no CPDOC, na documentação coletada muito cuidadosamente por Azeredo da Silveira. Apesar de restrições ou mesmo da falta de acesso a documentos provenientes das forças armadas no Brasil, a tese de Matias dá um salto qualitativo muito expressivo com relação à ampliação de fontes documentais e, consequentemente, à narrativa sobre o governo Geisel. Enxerga-se melhor pontos nebulosos, até então, na história diplomática brasileira, como o tão polêmico voto brasileiro a favor da resolução da Assembleia Geral que considerou o sionismo como uma forma de racismo, em 1975 (anulada pela Assembleia Geral de 1991). 0 voto teve mais a ver com as relações do Brasil com os Estados Unidos do que com os palestinos, Israel ou os países árabes exportadores de petróleo.

\section{RM}

E mais recentemente, depois do fim da Guerra Fria?

\section{NBS}

Hoje preocupa o problema da desestabilização no Oriente Médio e o fenômeno do terrorismo internacional. Para compreendê-los foca-se muito nos atentados de 11/9 e sobre a Guerra ao Iraque (segunda Guerra do Golfo), de 2003. Creio que é preciso prestar mais atenção à primeira Guerra do Golfo (1990-1991) e às resoluções aprovadas 
pelo Conselho de Segurança da ONU, que tiveram escopo amplíssimo, ultrapassando o que seria da competência do Conselho de Segurança. Enfim, foi um conjunto inédito de severas medidas contra o Iraque, que se mostraram ineficientes e com efeitos deletérios. Em 1998-1999, o Brasil estava no Conselho de Segurança, que tomava decisões com relação ao Iraque pela falta de acordo entre seus membros. Estados Unidos e Reino Unido insistiam sobre a necessidade de adotar novas medidas coercitivas para fazer Saddam Hussein atender às resoluções do Conselho. Em dezembro de 1998, sem o consentimento do Conselho, Estados Unidos e Reino Unido acabam bombardearam o Iraque durante três dias. Em janeiro, o Brasil assumiu a presidência do órgão; propôs e foi aprovada criação de três painéis que deveriam fazer recomendações sobre a situação iraquiana. Com a Guerra do Golfo de 2003, esses esforços praticamente desaparecem da memória. Entretanto, a literatura especializada indica que os três painéis criados em 1999 conduziram a uma sensível diminuição das tensões entre os membros do Conselho de Segurança e possibilitou construir um mínimo de consenso a propósito de medidas a serem tomadas com relação ao Iraque.

\section{RM}

Há um continuísmo em termos de política externa ou a sra. diria que houve uma mudança ou intensificação nos últimos governos?

\section{NBS}

A política externa do governo Dilma teve um contraste muito forte com relação ao governo de Lula. Lula contou com um contexto internacional favorável. Utilizou seu carisma no exercício da diplomacia presidencial e contou ainda com uma relação de grande sinergia com o ministro Celso Amorim. A presidente Dilma enfrentou crises nas frentes externa e interna, e engajou-se muito limitadamente no plano internacional. Portanto, o reconhecido ativismo do presidente Lula não teve continuidade, embora não se possa falar tampouco de ruptura na política externa das duas presidências. De toda forma, é necessário ter em mente que proximidade temporal que nos separa dos governos Lula e Dilma. Temos uma razoável quantidade de informações, mas não podemos esquecer que muitas fontes não ainda estão acessíveis. Além disso, a polarização que tem marcado a sociedade brasileira nos últimos anos, e que provavelmente não se alterará de maneira significativa a curto prazo, contamina demasiadamente o debate sobre os períodos muito recentes sobre a política externa brasileira.

Com relação ao Oriente Médio, conheço um pouco melhor a política externa de Lula. Embora as avaliações sejam divergentes sobre os resultados de sua política externa, creio que há consenso sobre o ativismo e o perfil alto de sua diplomacia, denominada pelo próprio governo como "ativa e altiva". É preciso ainda qualificar melhor esse ativismo que pode revelar-se voluntarista em certos empreendimentos. 0 que para mim diferenciou o governo Lula de períodos anteriores foram sobretudo suas iniciativas no campo da paz e da segurança internacional, que não se circunscreveram ao entorno regional do Brasil, área 


\section{entrevista}

tradicional da atuação brasileira. E foi justamente no Oriente Médio que essas iniciativas aconteceram. O Brasil buscou participar dos esforços de mediação do conflito entre Israel e os palestinos, e, com a Turquia, buscou mediar o conflito sobre o projeto nuclear iraniano. Outra marca da política externa do governo Lula foi a diplomacia de cúpulas visando à cooperação Sul-Sul. Nesse âmbito, nos interessa aqui sobretudo as Cúpulas América do Sul-Países Árabes (ASPA), que marcam uma aproximação entre América do Sul e Oriente Médio. Os fluxos comerciais entre o Brasil e o Oriente Médio aumentaram de maneira significativa no período Lula, provavelmente em parte como resultado da ASPA.

Enfim, indiquei questões que merecem maior problematização. Creio que é chegado o momento de começar a revisitar a política externa de Lula e de Dilma Rousseff. 0 tempo permite uma avaliação mais criteriosa, crítica e desapaixonada das decisões, ou da eventual falta de decisões, no âmbito da política externa do país. 